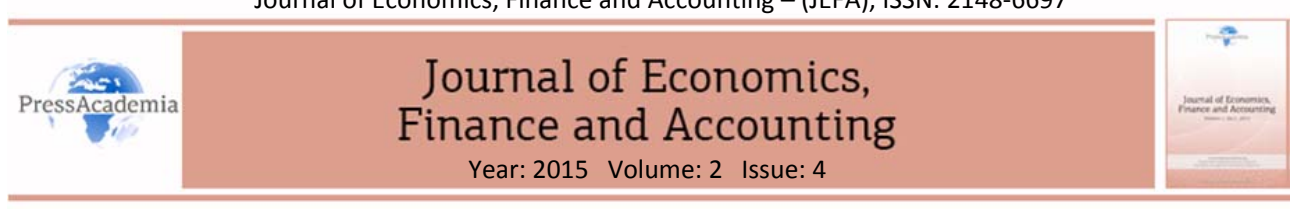

\title{
COMPARISON OF FINANCIAL PERFORMANCE OF PARTICIPATION BANKS IN TURKEY
}

DOI: 10.17261/Pressacademia.2015414373

\section{Mesut Dogan'}

'Afyon Kocatepe University. mesutdogan@aku.edu.tr

\section{Keywords}

Gray Relational Analysis, Financial Performance,

Participation banks

JEL Classification

G21, L21, L25

\section{ABSTRACT}

Aim of this study is to apply Gray Relational Analysis (GRA) to measure and compare financial performances of participation banks between the years of 2012-2014. Another aim of the study is to reduce the number of financial rates, which determine participation bank performance, and by doing so, identify which financial rate is more important in performance measurement. As a result of GRA method, "Albaraka Turk" is the first and "Bank Asya" is the last in terms of financial performance. Another finding of the study is that a participation bank with high "Return on Assets" could also have a high financial performance.

\section{TÜRKIYE'DE KATILIM BANKALARININ FINANSAL PERFORMANSLARININ KARŞILAŞTIRILMASI}

\section{Anahtar Kelimeler}

Gri İlişkisel Analiz, Finansal Performans, Katılım Bankası

JEL Sınıflandırması G21, L21, L25

\section{ÖZET}

Bu çalışmanın amacı 2012-2014 yıllarını arasında Türkiye'de Bankacılık Sektöründe faaliyette bulunan katılım bankaların finansal performansları Gri îlişkisel Analiz (GIA) yöntemi kullanılarak karşılaştırılmıştır. Araştırmanın bir diğer amacı ise katılım bankasının performansını belirleyen finansal oranların sayısını azaltmak ve bu sayede hangi finansal oranın performans ölçümünde daha önemli olduğunu tespit etmektir. GIA yöntemi sonucunda finansal performans bakımından ilk sırada "Albaraka Türk" son sırada ise "Bank Asya" yer almıştır. Araştırma sonucunda elde edilen bir diğer bulgu ise "Varlık Karlılığı" yüksek olan bir katılım bankasının finansal performansının da yüksek olabileceği sonucuna ulaşılmıştır. 


\section{GíRiş}

Bankacılık sektörü ekonominin gelişmesi açısından en önemli aktörlerden biridir. Bankalar, sermaye birikimi, firmaların büyümesi ve ekonomik zenginliğin sağlanması açısından ekonomide önemli bir role sahiptir (Taşkın, 2011: 289). Rekabet şartlarının üst düzey olduğu günümüz finans sektörü koşulları, bankaları kaynaklarını en etkin biçimde kullanmaya zorlamaktadır. Bu durum da, karar verici konumundaki banka yöneticilerinin, kendi bankalarının etkinliklerini bulundukları sektör içindeki rakip bankaların etkinlikleri ile karşılaştırma ihtiyacını ortaya çıkartmaktadır (Budak, 2011: 96).

Kar ve zarara katılma esasına göre çalışan ve risk paylaşımını öngören sistem, dünyada daha çok faizsiz bankacılık (interest-free banking) ya da İslami bankacılık (islamic banking) olarak bilinmesine rağmen, Türkiye'de Katılım Bankacılığı (participation banking) olarak bilinmektedir (Parlakkaya ve Çürük, 2011). Finansal sistem içerisinde giderek önemli bir yer edinen Katılım Bankaları, Türkiye'de faaliyetlerine ilk olarak 1983 yılında özel finans kurumları adıyla başlamıştır. Özel finans kurumlarının kuruluş amacı, toplumda faiz hassasiyeti olan kişilerin tasarruflarını ekonomiye kazandırmak ve benzer nitelikteki yabancı fonların ülkeye gelmesini sağlamaktır. 2005 yılından itibaren bankalar kanunu kapsamına alınarak Katılım Bankaları sıfatını kazanan bu kurumlar, Ziraat Katılım bankasının da eklenmesiyle Türkiye'de 5 banka ile faaliyet göstermektedir (Baykara, 2012).

Katılım bankalarının ekonomiye farklı açılardan katkısı vardır. Finansal sisteme girmeyen fonların sisteme kazandırarak, tasarruf sahiplerine kazanç sağlaması, gelir dağılımını düzenleyici etkileri, reel sektöre kaynak aktararak ekonominin büyümesine olan katkıları söylenebilir. Bununla birlikte kayıt dışı ekonomik faaliyetlerin kayıt altına alınması, Kurumlar Vergisi, KDV, KKDF ve BSMV ödeyerek kamu maliyesine katkıları, reel sektörün doğrudan fonlanması sebebi ile istihdamın sürekliliği ve artışı ile sosyo-kültürel faaliyetlere katkıları da sayılabilir (Ece, 2011).

Katılım bankacılığında önemli bir gelişme, banka isim ve statüsünün kazanıldığı 5411 sayılı Bankacılık Kanunu'nun yürürlüğe girmesiyle 2005 yılından sonra meydana gelmiştir. 2013 yılı sonunda katılım bankalarının payı aktifte \%5,5'e, toplanan fonlarda \%6,5'e, kullandırılan fonlarda ise \%6,1'e yükselmiştir. Ancak Bank Asya'nın yönetimi TMFS'ye devredilmesinden dolayı 2014 sonunda her üç kalemde de katılım bankalarının payı çok küçük oranlarda gerilemiştir. Bu oranlar aktif, toplanan ve kullandırılan fonlar itibarıyla sırasıyla; \%5,2, \%6,2 ve \%5,4 şeklinde gerçekleşmiştir. Katılım bankalarının payının \%1'lerden \%6'lara yükselmesi sektörün istikrarlı ve hızlı bir büyüme sürecine girdiğini göstermektedir. Nitekim toplam bankacılık sektörü 2005 yılından sonra \%20 oranında büyürken katılım bankacılığında \%30’lar seviyesinde büyüme gerçekleşmiştir (TKBB, 2014: 5). Sektörün bu kadar hızlı ve istikrarlı bir şekilde büyümesiyle birlikte 2015 yılında tamamı kamuya ait Ziraat Bankası, Ziraat Katılım Bankası'nı kurmuş ve faaliyete başlamıştır. Benzer şekilde önemli bir kısmı kamuya ait olan Halk Bankası'nın ve Vakıf Bankası'nın katılım bankası kurmak için gerekli izinleri almıştır. Bu bankaların da sektöre girmesiyle katılım bankaların toplam bankacılık sektörü içerisindeki payı ve dolayısıyla katılım bankaları içerisinde rekabette artacaktır. 
Mart 2014 itibarıyla Türk Bankacılık Sektörü 49 banka 12.033 adet şube ve 215.289 personel ile faaliyet göstermektedir. 2014 yılının ilk çeyreğindeki personel sayısında 1.063 kişi, şube sayısında ise 47 adet artış gerçekleşmiştir. Sektör 843 adet yurtdışı şube ve 10 adet temsilcilikle toplamda 17 ülkede faaliyet göstermekte, iştirakler de dâhil edildiğinde ülke sayısı 33'e yükselmektedir (BDDK, 2014). Katılım bankalarının ise yurtiçinde toplam 1064 şubesi bulunmaktadır. Albaraka Türk Katılım Bankası'nın 209, Bank Asya'nın 200, Kuveyt Türk Katılım Bankası'nın 353, Türkiye Finans Katılım Bankası'nın 286 ve Ziraat Katılım Bankası'nın 16 şubesi bulunmaktadır (TKBB, 2015).

Bu çalışmada 2012-2014 yıllarını arasında Türk Bankacılık Sektöründe faaliyette bulunan katılım bankaların finansal performansları Gri ìlişkisel Analiz (GiA) yöntemi kullanılarak karşılaştırılmıştır. Araştırmanın bir diğer amacı ise katılım bankasının performansını belirleyen finansal oranların sayısını azaltmak ve bu sayede hangi finansal oranın performans ölçümünde daha önemli olduğunu tespit etmektir.

Çalışma beş bölümden oluşmaktadır. Girişi takiben ikinci bölümde GiA yöntemini uygulayarak bankaların finansal performansını ölçen çalışmalar özetlenmiştir. Üçüncü bölümünde GIA yönteminin hesaplama adımları gösterilmiş ve dördüncü bölümde ise GiA uygulaması yer almıştır. Son bölümde ise araştırmanın sonuçları irdelenerek genel bir değerlendirme yapılmıştır.

\section{LITERATÜR TARAMASI}

Gri İlişkisel Analiz yöntemi uygulanan pek çok çalışma vardır. Gri ilişkisel analiz yöntemi havayolu ağlarının tasarımında (Hsu ve Wen, 2000), işletmelerin finansal göstergelerinin kıyaslanmasında (Feng ve Wang, 2000), satış tahminlerinde (Lin ve Hsu, 2002) ve birçok sektörde kullanılmıştır. Bu bölümde GiA yöntemi ile finansal göstergeleri kıyaslayan çalışmalar ve Katılım bankaların finansal performansını ölçen araştırmalar özetlenmiştir.

Ho ve Wu (2006) Avusturalya'da faaliyette bulunan 3 bankanın 23 rasyosunu Gri ilişkisel Analiz yöntemi kullanarak likidite, finansal kaldıraç ve karlıık oranları yardımıyla performansını karşılaştırmışlardır. Araştırmalarının sonucunda likit oranları yüksek olan bankaların performansın da yüksek olabileceğini tespit etmişlerdir.

Chang (2006) Tayvan'daki 15 ticari bankanın gri ilişkisel analiz yöntemi kullanarak performansını incelemiştir. 2000-2002 yıllarının verilerini kullandığı çalışmasında likidite, sermaye yapısı ve kârlılık oranlarından oluşan 20 tane rasyo kullanmıştır. Çalışma sonucunda ticari bankaların performansını etkileyen en önemli oranların "Varlık Karlılı̆ı" daha sonra ise "Öz Sermaye Karlılığı" olduğunu belirlemiştir.

Yuan (2007) 6 firmanın likidite ve karlılık oranları yardımıyla performansını karşılaştırmıştır. 10 tane finansal oran ve GiA yöntemi kullandığı çalışmasının sonucunda firma performans ölçmede en önemli oranın karlılık oranları olduğunu tespit etmiştir. Lee, Lin ve Shin (2012), Tayvan ve Kore'deki nakliye firmalarının finansal performansını karşılaştırmak amacıyla GiA yöntemini kullanmışlardır. Çalışmasının sonucunda finansal oranlar önem dereceleri belirlenerek nakliye firmalarını finansal performanslarına göre sıralamışlardır. 
Peker ve Baki (2011) Sigorta sektöründe faaliyet gösteren üç şirketi finansal performanslarına göre sıralamışlardır. Gri illişkisel Analiz yöntemi kullanılarak likidite, kaldıraç ve kârlııık oranları yardımıyla performans ölçülmüş ve analiz sonucunda likidite oranları yüksek olan bir sigorta şirketinin finansal performansının da yüksek olabileceği sonucuna varmışlardır.

Uçkun ve Girginer (2011) Kamu ve özel mevduat bankalarının finansal oranlar yardımıyla Gri İlişki Analizi (GIA) kullanılarak finansal performanslarının belirlenmesi amaçlanmıştır. Finansal başarıdaki en önemli finansal oranlar kamu bankalarında kârlılıkla ilgili oranlar, özel bankalarda ise aktif kalitesiyle ilgili oranlar olarak tespit etmişlerdir. Girginer ve Uçkun (2012) finansal krizin Türk ticari bankaların performansına etkisini Gri illişkisel Analiz (GIA) yöntemini uygulayarak ölçmüşlerdir. 2005-2009 yıllarının verilerinden yararlandıkları çalışmalarında performans göstergesi olarak, bankaların karlıık, likidite, aktif kalite ve sermaye yeterliliği ile ilgili oranları kullanmışlardır. GIA yöntemi sonucunda performans sıralaması kamu bankaları, yabancı bankalar ve özel bankalar şeklinde olmuştur.

Elitaş vd. (2012) 2010-2011 yıllarında iMKB'de işlem gören sigorta şirketlerine GIA yöntemi kullanılarak finansal performanslarını tespit etmişlerdir. Çalışmada 10 finansal oran kullanılarak, likidite, kaldıraç ve kârlııı oranları yardımıyla performans ölçümünde bulunulmuştur. GIA sonucunda finansal performans bakımından ilk sırada Aksigorta yer almıştır. Ayrıca çalışmada sigorta şirketlerinin finansal başarısında en önemli rasyonun likidite oranları olduğu sonucuna varılmıştır.

Ecer ve Dündar (2012) Türk bankacılık sektöründe yer alan özel sermayeli mevduat bankalarının performansını değerlendirmişlerdir. 2010 yılına ilişkin sermaye yeterliliği, likidite ve gelir-gider yapısı rasyolarından yararlanılarak Türkiye'de faaliyet gösteren 11 özel sermayeli mevduat bankasının performansları GIA yaklaşımıyla ölçmüşlerdir. GIA yöntemi sonucunda en iyi performansa sahip özel sermayeli mevduat bankalarının sırasıyla Adabank, Garanti Bankası ve Tekstil Bank olduğunu belirlemişlerdir. Benzer bir şekilde Doğan, (2013) GIA yöntemi uygulanarak 2005- 2011 yılları arasında iMKB' de hisse senetleri işlem gören 10 bankanın finansal performansını karşılaştırmıştır. GiA yöntemi sonucunda finansal performansı en yüksek "Akbank", en düşük ise "Yapı Kredi Bankası" olarak belirlenmiştir.

Çetin ve Bıtırak (2010) özel kesim ticari bankalar ile katılım bankalarının 2005-2007 yılları için finansal performansı AHP yöntemi ile ölçmüşlerdir. AHP yöntemi sonucunda katılım bankaları içerisinde Bank Asya'nın en yüksek performans gösterdiğini tespit etmişlerdir.

Yayar ve Baykara (2012) Katılım bankalarının 2005-2011 yılları arasındaki faaliyetlerinin etkinlik ve verimlilikleri TOPSIS yöntemi ile ölçmüşlerdir. Çalışma sonucunda Albaraka Türk en etkin, Bank Asya ise en verimli banka olduğu belirlenmiştir.

\section{GRI iLişKISEL ANALIZ}

Gri teori ilk kez 1982 yılında Julong Deng tarafından geliştirilmiştir (Deng, 1989). Buradaki gri ifadesi bilginin eksik olmasını ya da hiç bilinmemesini anlatmaktadır. Son yirmi yılda gri sistem teorisi farklı alanlarda kullanılan önemli bir analiz yöntemi haline gelmiştir. Gri sistem teorisi belirsizliğin sayısallaştırılmasında alternatif bir metottur. Bu teori temel 
olarak sistemler arasındaki ilişkinin analizi, model kurulması, tahmin ve karar problemlerinde sıkça kullanılan bir yöntemdir (Üstünışık, 2007). Gri İlişkisel Analiz; çok kriterli karar problemlerindeki belirsizlikleri analiz etmek amacıyla kullanılan yöntemlerden biri olup, belirsizliğin söz konusu olduğu durumlarda matematiksel analiz yöntemlerine oranla daha kolay çözüm sunar. (Peker, Baki, 2011). Gri iliş̧kisel Analiz, gri bir sistemdeki her bir faktör ile kıyas yapılan faktör (referans serisi) serisi arasındaki ilişki derecesini belirlemeye yarayan bir metottur. Her bir faktör bir dizi (satır veya sütun) olarak tanımlanır. Faktörler arası etki derecesi ise gri ilişkisel derece olarak isimlendirilir (Üstünışık, 2007).

Gri ilişkisel analiz metodunun hesaplama adımları aşağıdaki gibidir (Wen, 2004).

1. adım: Karar matrisinin $\left(X_{i}\right)$ oluşturulması

$$
\mathbf{X}_{i}=\left[\begin{array}{llll}
x_{1}(1) & x_{1}(2) & \ldots & x_{1}(n) \\
x_{2}(1) & x_{2}(2) & \ldots & x_{2}(n) \\
\vdots & \vdots & \ddots & \vdots \\
x_{n}(1) & x_{n}(2) & \ldots & x_{n}(n)
\end{array}\right]
$$

\section{2. adım: Referans serisinin oluşturulması}

Referans serisi $x_{0}=\left(x_{0}(1), x_{0}(2), \ldots, x_{0}(j), \ldots, x_{0}(n)\right)$ şeklinde ifade edilir. Ifadedeki $x_{0}(j), j$. kriterin normalize değerleri içindeki en büyük değerini göstermektedir.

\section{3. adım: Normalizasyon işlemi}

Bu adımda veriler normalize edilir. 3 durum ile karşılaşılabilir.

Eğer kriter değerinin normalize işleminin sonra büyük çıkması daha uygun ise,

$$
x_{i}^{*}(j)=\frac{x_{i}(j)-\min _{j} x_{i}(j)}{\max _{j} x_{i}(j)-\min _{j} x_{i}(j)}
$$

formülü kullanılır. Kriter değerinin normalize işleminin sonra küçük çıkması daha uygun ise,

$$
x_{i}^{*}(j)=\frac{\max _{j} x_{i}(j)-x_{i}(j)}{\max _{j} x_{i}(j)-\min _{j} x_{i}(j)} .
$$

formülünden yararlanılır. Üçüncü durum ise eğer kriter değerinin normalize işleminin ardından ortalama bir değer alması daha uygun ise,

$$
x_{i}^{*}(j)=\frac{\left|x_{i}(j)-x_{0 b}(j)\right|}{\max _{j} x_{i}(j)-x_{0 b}(j)} .
$$


formülü kullanııır. (4) numaralı formülde $X_{0 b}(j) j$. kriterin hedef değeridir ve

$$
\max _{j} x_{i}(j) \geq x_{0 b}(j) \geq \min _{j} x_{i}(j)
$$

aralığında bir değer alır. Bu işlemlerin ardından (1)'deki karar matrisi aşağıdaki duruma dönüşür:

$$
\mathbf{X}_{i}^{*}=\left[\begin{array}{llll}
x_{1}^{*}(1) & x_{1}^{*}(2) & \ldots & x_{1}^{*}(n) \\
x_{2}^{*}(1) & x_{2}^{*}(2) & \ldots & x_{2}^{*}(n) \\
\vdots & \vdots & \ddots & \vdots \\
x_{n}^{*}(1) & x_{n}^{*}(2) & \ldots & x_{n}^{*}(n)
\end{array}\right]
$$

4. adım: Mutlak değer tablosunun oluşturulması

$x_{0}^{*}$ ile $x_{i}^{*}$ arasındaki mutlak değer $\Delta_{o i}(j)$ şöyle bulunur:

$$
\begin{aligned}
& \Delta_{0 i}(j)=\left|x_{0}^{*}(j)-x_{i}^{*}(j)\right| \\
= & {\left[\begin{array}{llll}
\Delta_{01}(1) & \Delta_{01}(2) & \ldots & \Delta_{01}(n) \\
\Delta_{02}(1) & \Delta_{02}(2) & \ldots & \Delta_{02}(n) \\
\vdots & \vdots & \ddots & \vdots \\
\Delta_{0 m}(1) & \Delta_{0 m}(2) & \ldots & \Delta_{0 m}(n)
\end{array}\right] }
\end{aligned}
$$

5. adım: Gri ilişkisel katsayı matrisinin oluşturulması

$\gamma_{0 i}(j)=\frac{\Delta \min +\zeta \Delta \max }{\Delta_{0 i}(j)+\zeta \Delta \max }$

formülü kullanılarak hesaplanır. (7) numaralı formülde $\zeta$ ayırııı (distinguish) katsayısıdır ve $[0,1]$ aralığında değer alır. Ancak işlemlerde 0.5 alınması tavsiye edilmektedir. Ayrıca $\Delta \max =\max _{i} \max _{j} \Delta_{o i}(j)$ ve $\Delta \min =\min _{i} \min _{j} \Delta_{o i}(j)$ şeklinde hesaplanır.

6. adım: Ilişki derecesinin hesaplanması

$$
\Gamma_{o i}=\frac{1}{n} \sum_{j=1}^{n} \gamma_{o i}(j)
$$

(8) numaralı formülde $\Gamma_{o i} i$. elemanın gri ilişki derecesini göstermektedir ve kriterlerin eşit önem düzeyinde olduğu varsayıldığında kullanııı. Eğer kriterlerin farklı ağırıkları söz konusu ise 


$$
\Gamma_{o i}=\sum_{j=1}^{n}\left[W_{i}(j) x \gamma_{o i}(j)\right]
$$

formülünden yararlanııır.

\section{METODOLOJi}

Bu çalışmada 2012-2014 yıllarını arasında Türk Bankacılık Sektöründe faaliyette bulunan katılım bankaların finansal performansları Gri illişkisel Analiz yöntemi kullanılarak karşılaştırılmıştır. Araştırmada sermaye yeterliliği, bilanço yapısı, aktif kalitesi, likidite, karlıık oranları yardımıyla ve Gri ilişkisel Analiz yöntemi kullanılarak katıım bankaların performansları ölçülmüşsür. Analize dahil edilen bankalar; Bank Asya, Kuveyt Türk, Albaraka, Türkiye Finans'tır. Ziraat Katılım bankası 2015 yılında faaliyete başlamasından dolayı analize dahil edilememiştir. Araştırmanın bir diğer amacı ise banka performansını belirleyen finansal oranların sayısını azaltmak ve bu sayede hangi finansal oranın performans ölçümünde daha önemli olduğunu tespit etmektir. Gri ilişkisel analiz yönteminde kullanılan veriler Türkiye Katılım Bankaları Birliği'nin veri tabanından sağlanmışıı. Çalışmada sermaye yeterliliği, bilanço yapısı, aktif kalitesi, likidite, karlılık oranları yardımıyla 4 katılım bankasının performansı incelemiştir. Araştırmada kullanılan oranlar Tablo 1'de gösterilmiştir.

Tablo 1: Finansal Oranlar

\begin{tabular}{|l|l|c|}
\hline Oran Türü & \multicolumn{1}{|c|}{ Oran } & Kodu \\
\hline \multirow{2}{*}{ Sermaye Yeterliliği } & Özkaynaklar/Toplam Aktifler & $\mathrm{A} 1$ \\
\cline { 2 - 3 } & (Özkaynaklar-Duran Varlıklar)/Toplam Aktifler & $\mathrm{A} 2$ \\
\hline \multirow{2}{*}{ Bilanço Yapısı } & Toplam Toplanan Fonlar/Toplam Aktifler & $\mathrm{A} 3$ \\
\cline { 2 - 3 } & Alınan Krediler/ Toplam Aktifler & $\mathrm{A} 4$ \\
\hline \multirow{3}{*}{ Aktif Kalitesi } & Toplam Krediler ve Alacaklar/Toplam Aktifler & $\mathrm{A} 5$ \\
\cline { 2 - 3 } & $\begin{array}{l}\text { Toplam Krediler ve Alacaklar/ Toplam Toplanan } \\
\text { Fonlar }\end{array}$ & $\mathrm{A} 6$ \\
\hline \multirow{2}{*}{ Kikidite } & Likit Aktifler/ Kısa Vadeli Yükümlükler & $\mathrm{A} 7$ \\
\cline { 2 - 3 } & Likit Aktifler/Toplam Aktifler & $\mathrm{A} 8$ \\
\hline & Net Kar/Toplam Aktifler & $\mathrm{A} 9$ \\
\cline { 2 - 3 } & Net Kar/ Öz kaynaklar & $\mathrm{A} 10$ \\
\hline
\end{tabular}

\section{KATILIM BANKALARININ FINANSAL PERFORMANSLARININ ÖLÇÜLMESI}

Bu çalışmada Türkiye'de Bankacılık Sektöründe faaliyette bulunan 4 katılım bankasının GiA yöntemi kullanılarak finansal performanslarının ölçülmesi amaçlanmıştır. Bu amaçla 20122014 yıllarında finansal verileri kullanılarak örneklem oluşturulmuştur.

\subsection{Karar Matrisinin Oluşturulması}

Bankaların mali tablolarından elde edilen verilerle hesaplanan ve 3 yıllık finansal oranların ortalaması alınarak Tablo 1'de karar matrisi oluşturulmuştur. 
Tablo 2: Bankalara Ait Karar Matrisi

\begin{tabular}{|l|c|c|c|c|c|c|c|c|c|c|}
\hline & \multicolumn{2}{|c|}{$\begin{array}{c}\text { Sermaye } \\
\text { Yeterliliği }\end{array}$} & \multicolumn{2}{c|}{ Bilanço Yapısı } & \multicolumn{2}{c|}{ Aktif Kalitesi } & \multicolumn{2}{c|}{ Likidite } & \multicolumn{2}{c|}{ Karlıık } \\
\hline BANKALAR & A1 & A2 & A3 & A4 & A5 & A6 & A7 & A8 & A9 & A10 \\
\hline Albaraka Türk & 0,088 & 0,061 & 0,733 & 0,124 & 0,701 & 0,956 & 0,222 & 0,43 & 0,013 & 0,153 \\
\hline Bank Asya & 0,045 & $-0,05$ & 0,439 & 0,074 & 0,469 & 1,052 & 0,143 & 0,268 & 0,002 & 0,024 \\
\hline Kuveyt Türk & 0,089 & 0,061 & 0,661 & 0,173 & 0,617 & 0,933 & 0,327 & 0,717 & 0,012 & 0,134 \\
\hline Türkiye Finans & 0,105 & 0,061 & 0,607 & 0,201 & 0,702 & 1,158 & 0,235 & 0,439 & 0,013 & 0,123 \\
\hline
\end{tabular}

Tablo 2' de sermaye yeterlilik oranları incelendiğinde (A1- A2) en yüksek Türkiye Finans, en düşük ise Bank Asya'dır. Bilanço yapısına bakıldığında ise (A3- A4) aktifler içerisinde fonların ağırlığı en fazla olan banka Albaraka Türk, en düşük olan ise Bank Asya'dır.

Bankaların aktif kalitesi incelendiğinde (A5- A6) toplam aktif içerisindeki kredi oranı en düşük olan Bank Asya, en yüksek ise Türkiye Finans'tır. Kısa vadeli borç ödeme gücü (A7A8) en yüksek olan Kuveyt Türk, en düşük ise Bank Asya'dır.

Bankaların karlılık oranlarına bakıldığında (A9- A10) varlık karlılığı (A9) en yüksek olan Albaraka Türk, en düşük ise Bank Asya'dır. Öz sermaye karlılığı (A10) en yüksek olan Albaraka Türk, en düşük ise Bank Asya'dır. Bir başka ifade ile karlılık bakımından Bank Asya diğer bankalardan daha kötü durumdadır.

\subsection{Referans Serisinin Oluşturulması}

Tablo 3'te hayali bir referans firmanın değerleri eklenmiştir. Bu adımda belirtilen referans serisi her kriterdeki en büyük değerler alınarak oluşturulmuştur.

Tablo 3: Bankalara Ait Referans Serisi Oluşturulmuş Karar Matrisi

\begin{tabular}{|l|c|c|c|c|c|c|c|c|c|c|}
\hline & \multicolumn{2}{|c|}{$\begin{array}{c}\text { Sermaye } \\
\text { Yeterliliği }\end{array}$} & \multicolumn{2}{c|}{$\begin{array}{c}\text { Bilanço } \\
\text { Yapısı }\end{array}$} & \multicolumn{2}{c|}{$\begin{array}{c}\text { Aktif } \\
\text { Kalitesi }\end{array}$} & \multicolumn{2}{c|}{ Likidite } & \multicolumn{3}{c|}{ Karlılık } \\
\hline BANKALAR & A1 & A2 & A3 & A4 & A5 & A6 & A7 & A8 & A9 & A10 \\
\hline X Bankası & 1,00 & 1,00 & 1,00 & 1,00 & 1,00 & 1,00 & 1,00 & 1,00 & 1,00 & 1,00 \\
\hline Albaraka Türk & 0,088 & 0,061 & 0,733 & 0,124 & 0,701 & 0,956 & 0,222 & 0,43 & 0,013 & 0,153 \\
\hline Bank Asya & 0,045 & $-0,05$ & 0,439 & 0,074 & 0,469 & 1,052 & 0,143 & 0,268 & 0,002 & 0,024 \\
\hline Kuveyt Türk & 0,089 & 0,061 & 0,661 & 0,173 & 0,617 & 0,933 & 0,327 & 0,717 & 0,012 & 0,134 \\
\hline Türkiye Finans & 0,105 & 0,061 & 0,607 & 0,201 & 0,702 & 1,158 & 0,235 & 0,439 & 0,013 & 0,123 \\
\hline
\end{tabular}

\subsection{Karşılaştırma Serisinin Oluşturulması}

Şirket yöneticileri ve hissedarları her zaman firma karlılığının ve kısa vadeli ödeme gücünün yüksek olmasını isterler. Bu yüzden likidite ve kârlılık oranlarında (2) numaralı formül kullanılmıştır. Kaldıraç oranları firmanın borç yükünü gösterdiği için özellikle kredi verenler açısından düşük olması istenir. Bu nedenle kaldıraç oranlarında (3) numaralı formül kullanılarak hesaplanmıştır. Ancak varlık içerisindeki öz kaynak oranının (A8) yüksek olması istendiği için (2) numaralı formül kullanılmıştır. Aktif kalitesi ile ilgili oranların yüksek çıkması yüksek kredilendirme düzeyini ifade eder, banka açısından yüksek kredi riski anlamı taşımaktadır. Bu oranların düşük çıkması ise bankaların aktif kalitesini olumsuz yönde etkilemektedir. Bu yüzden bu oranların optimal bir değer alması gerekir ve (4) numaralı formül kullanılarak hesaplanmıştır. 
Tablo 4: Bankalara Ait Karşılaştırma Serisi Tablosu

\begin{tabular}{|c|c|c|c|c|c|c|c|c|c|c|}
\hline & \multicolumn{2}{|c|}{$\begin{array}{c}\text { Sermaye } \\
\text { Yeterliliği }\end{array}$} & \multicolumn{2}{c|}{$\begin{array}{c}\text { Bilanço } \\
\text { Yapısı }\end{array}$} & \multicolumn{2}{c|}{$\begin{array}{c}\text { Aktif } \\
\text { Kalitesi }\end{array}$} & \multicolumn{2}{c|}{ Likidite } & \multicolumn{2}{c|}{ Karlılık } \\
\hline BANKALAR & A1 & A2 & A3 & A4 & A5 & A6 & A7 & A8 & A9 & A10 \\
\hline X Firması & 1,00 & 1,00 & 1,00 & 1,00 & 1,00 & 1,00 & 1,00 & 1,00 & 1,00 & 1,00 \\
\hline Albaraka Türk & 0,28 & 0,00 & 0,00 & 0,39 & 0,01 & 0,90 & 0,57 & 0,64 & 0,00 & 0,00 \\
\hline Bank Asya & 1,00 & 1,00 & 1,00 & 0,00 & 1,00 & 0,47 & 1,00 & 1,00 & 1,00 & 1,00 \\
\hline Kuveyt Türk & 0,27 & 0,01 & 0,24 & 0,78 & 0,37 & 1,00 & 0,00 & 0,00 & 0,14 & 0,15 \\
\hline Türkiye Finans & 0,00 & 0,00 & 0,43 & 1,00 & 0,00 & 0,00 & 0,50 & 0,62 & 0,04 & 0,23 \\
\hline
\end{tabular}

\subsection{Mutlak Değer Tablosunun Oluşturulması}

Bu adımda (6) numaralı formül yardımıyla en büyük değerler ile diğer kriterlerdeki değerler arasındaki uzaklıklar bulunarak mutlak değer tablosu oluşturulmuştur. Başka bir ifade ile Bu adımda normalize edilmiş değerler ile referans serisi arasındaki uzaklıklar hesaplanmıştır.

Tablo 5:Bankalara Ait Mutlak Değer Tablosu

\begin{tabular}{|c|c|c|c|c|c|c|c|c|c|c|}
\hline & \multicolumn{2}{|c|}{$\begin{array}{c}\text { Sermaye } \\
\text { Yeterliliği }\end{array}$} & \multicolumn{2}{c|}{$\begin{array}{c}\text { Bilanço } \\
\text { Yapısı }\end{array}$} & \multicolumn{2}{c|}{$\begin{array}{c}\text { Aktif } \\
\text { Kalitesi }\end{array}$} & \multicolumn{2}{c|}{ Likidite } & \multicolumn{2}{c|}{ Karlılık } \\
\hline BANKALAR & A1 & A2 & A3 & A4 & A5 & A6 & A7 & A8 & A9 & A10 \\
\hline X Firması & 1,00 & 1,00 & 1,00 & 1,00 & 1,00 & 1,00 & 1,00 & 1,00 & 1,00 & 1,00 \\
\hline Albaraka Türk & 0,28 & 0,00 & 0,00 & 0,39 & 0,01 & 0,90 & 0,57 & 0,64 & 0,00 & 0,00 \\
\hline Bank Asya & 1,00 & 1,00 & 1,00 & 0,00 & 1,00 & 0,47 & 1,00 & 1,00 & 1,00 & 1,00 \\
\hline Kuveyt Türk & 0,27 & 0,01 & 0,24 & 0,78 & 0,37 & 1,00 & 0,00 & 0,00 & 0,14 & 0,15 \\
\hline Türkiye Finans & 0,00 & 0,00 & 0,43 & 1,00 & 0,00 & 0,00 & 0,50 & 0,62 & 0,04 & 0,23 \\
\hline
\end{tabular}

\subsection{Gri İlişkisel Katsayı Matrisi Tablosunun Oluşturulması}

Tüm finansal oranların gri ilişkisel katsayıya çevrilmesiyle $\delta=0,5$ alınarak (7) numaralı formülden yararlanarak Tablo 6 oluşturulmuştur.

Tablo 6: Gri iliş̧kisel Katsayı Matrisi Tablosu

\begin{tabular}{|l|c|c|c|c|c|c|c|c|c|c|}
\hline & \multicolumn{2}{|c|}{$\begin{array}{c}\text { Sermaye } \\
\text { Yeterliliği }\end{array}$} & \multicolumn{2}{c|}{$\begin{array}{c}\text { Bilanço } \\
\text { Yapısı }\end{array}$} & \multicolumn{2}{c|}{$\begin{array}{c}\text { Aktif } \\
\text { Kalitesi }\end{array}$} & \multicolumn{2}{c|}{ Likidite } & \multicolumn{2}{c|}{ Karlılık } \\
\hline BANKALAR & A1 & A2 & A3 & A4 & A5 & A6 & A7 & A8 & A9 & A10 \\
\hline Albaraka Türk & 0,779 & 0,996 & 1,000 & 0,720 & 0,993 & 0,527 & 0,636 & 0,610 & 1,000 & 1,000 \\
\hline Bank Asya & 0,500 & 0,500 & 0,500 & 1,000 & 0,500 & 0,679 & 0,500 & 0,500 & 0,500 & 0,500 \\
\hline Kuveyt Türk & 0,790 & 0,995 & 0,804 & 0,562 & 0,732 & 0,500 & 1,000 & 1,000 & 0,874 & 0,869 \\
\hline Türkiye Finans & 1,000 & 1,000 & 0,701 & 0,500 & 1,000 & 1,000 & 0,667 & 0,618 & 0,960 & 0,812 \\
\hline
\end{tabular}

Gri ilişkisel katsayı matris tablosunda bankaların performanslarını belirleyen faktörlerin ağırlıkları yer almaktadır. Kriterlerin eşit önem düzeyinde olduğu varsayılmıştır ve her bir kriterin ağırlığı 0,10 olarak alınmıştır. Tablo 7 'de ise (8) numaralı formül yardımıyla bu 
faktörlerin ilişki derecesini ve Tablo 8'de ise bankaların performanslarına göre sıralanması yapılmıştır.

Tablo 7: Gri îlişkisel Katsayı Matrisi Değerlendirme Tablosu

\begin{tabular}{|l|c|c|c|c|c|c|c|c|c|c|}
\hline & \multicolumn{2}{|c|}{$\begin{array}{c}\text { Sermaye } \\
\text { Yeterliliği }\end{array}$} & \multicolumn{2}{c|}{$\begin{array}{c}\text { Bilanço } \\
\text { Yapısı }\end{array}$} & \multicolumn{2}{c|}{ Aktif Kalitesi } & \multicolumn{2}{|c|}{ Likidite } & \multicolumn{2}{c|}{ Karlılık } \\
\hline \multicolumn{1}{|c|}{ BANKALAR } & A1 & A2 & A3 & A4 & A5 & A6 & A7 & A8 & A9 & A10 \\
\hline Albaraka Türk & $\begin{array}{c}0,779 \\
(3)\end{array}$ & $\begin{array}{c}0,996 \\
(2)\end{array}$ & $\begin{array}{c}1,000 \\
(1)\end{array}$ & $\begin{array}{c}0,720 \\
(2)\end{array}$ & $\begin{array}{c}0,993 \\
(2)\end{array}$ & $\begin{array}{c}0,527 \\
(3)\end{array}$ & $\begin{array}{c}0,636 \\
(3)\end{array}$ & $\begin{array}{c}0,610 \\
(3)\end{array}$ & $\begin{array}{c}\mathbf{1 , 0 0 0} \\
(\mathbf{1})\end{array}$ & $\begin{array}{c}1,000 \\
(1)\end{array}$ \\
\hline Bank Asya & $\begin{array}{c}0,500 \\
(4)\end{array}$ & $\begin{array}{c}0,500 \\
(4)\end{array}$ & $\begin{array}{c}0,500 \\
(4)\end{array}$ & $\begin{array}{c}1,000 \\
(1)\end{array}$ & $\begin{array}{c}0,500 \\
(4)\end{array}$ & $\begin{array}{c}0,679 \\
(2)\end{array}$ & $\begin{array}{c}0,500 \\
(4)\end{array}$ & $\begin{array}{c}0,500 \\
(4)\end{array}$ & $\begin{array}{c}\mathbf{0 , 5 0 0} \\
(\mathbf{4})\end{array}$ & $\begin{array}{c}0,500 \\
(4)\end{array}$ \\
\hline Kuveyt Türk & $\begin{array}{c}0,790 \\
(2)\end{array}$ & $\begin{array}{c}0,995 \\
(3)\end{array}$ & $\begin{array}{c}0,804 \\
(2)\end{array}$ & $\begin{array}{c}0,562 \\
(3)\end{array}$ & $\begin{array}{c}0,732 \\
(3)\end{array}$ & $\begin{array}{c}0,500 \\
(4)\end{array}$ & $\begin{array}{c}1,000 \\
(1)\end{array}$ & $\begin{array}{c}1,000 \\
(1)\end{array}$ & $\begin{array}{c}\mathbf{0}, \mathbf{8 7 4} \\
(\mathbf{3})\end{array}$ & $\begin{array}{c}0,869 \\
(2)\end{array}$ \\
\hline Türkiye Finans & $\begin{array}{c}1,000 \\
(1)\end{array}$ & $\begin{array}{c}1,000 \\
(1)\end{array}$ & $\begin{array}{c}0,701 \\
(3)\end{array}$ & $\begin{array}{c}0,500 \\
(4)\end{array}$ & $\begin{array}{c}1,000 \\
(1)\end{array}$ & $\begin{array}{c}1,000 \\
(1)\end{array}$ & $\begin{array}{c}0,667 \\
(2)\end{array}$ & $\begin{array}{c}0,618 \\
(2)\end{array}$ & $\begin{array}{c}\mathbf{0 , 9 6 0} \\
(\mathbf{2})\end{array}$ & $\begin{array}{c}0,812 \\
(3)\end{array}$ \\
\hline
\end{tabular}

* Parantez içindeki rakamlar her bir finansal oran için sıralamayı göstermektedir.

Tablo 7'den görüldüğü gibi, Türkiye'de Bankacılık Sektöründe faaliyette katılım bankaların sermaye yeterlilik oranları incelendiğinde en yüksek olan Türkiye Finans en düşük ise Bank Asya'dır. Bankaların likidite oranları incelendiğinde en düşük olan Bank Asya, en yüksek Kuveyt Türk'tür. Bankaların karlılık oranlarına bakıldığında en yüksek Albaraka Türk en düşük ise Bank Asya'dır. Yapılan bu sıralama Gri İlişkisel Analiz yöntemi uygulanmadan önceki veya Tablo 2'den sonra yapılan sıralama ile uyuşmaktadır

Tablo 8. Performans Ölçümü Sonuçları ve Sıralamalar

\begin{tabular}{|l|c|c|}
\hline \multicolumn{1}{|c|}{ BANKALAR } & iLişKI DERECESi & SIRALAMA \\
\hline Albaraka Türk & 0,8261 & 4 \\
\hline Bank Asya & 0,5679 & 2 \\
\hline Türkiye Finans & 0,8258 & 3 \\
\hline Kuveyt Türk & 0,8126 & 4 \\
\hline
\end{tabular}


Şekil 1: Performans Ölçümü Sonuçları

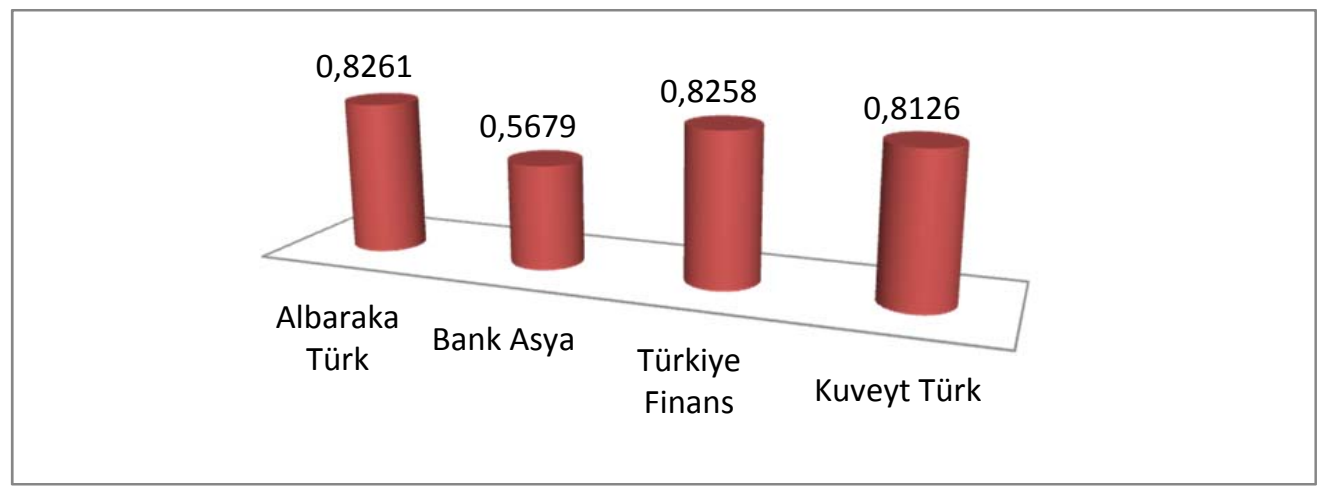

Bütün performans kriterleri beraber değerlendirildiğinde (Tablo 8 ve Şekil 1) ve katılım bankaları arasında genel bir sıralama yapıldığında performansı veya gri ilişki derecesi en yüksek olan Albaraka Türk'tür. İkinci sırada Türkiye Finans yer almakla birlikte, gri ilişkisel derecesi Albaraka Türk bankasına son derece yakındır. Başka bir ifade ile Türkiye Finans ile Albaraka Türk bankasının finansal performansları birbirine son derece yakındır. Performansı en düşük olan ise Bank Asya'dır. Performansı en yüksek olan Albaraka Türk'ü incelediğimizde diğer bankalardan ayıran temel kriter karlılık oranlarıdır. Başka bir ifade Albaraka Türk'ün diğer bankalardan Varlık Karlılığı (A9) daha yüksektir. Ayrıca performansı en düşük olan Bank Asya'nın Varlık Karlıı̆̆ı (A9) açısından sıralamada da en düşük olduğu görülmektedir. Varlık karlılığı finansal oranın sıralaması ile genel performans sıralamasının aynı olduğu görülmektedir. Sonuç itibariyle Varlık Karlılı̆ı yüksek olan bir katılım bankasının finansal performansının da yüksek olabileceği sonucuna ulaşılmıştır. Başka bir ifade ile katılım bankaların finansal başarısında en önemli göstergenin karlılık oranları olduğu tespit edilmiştir.

\section{GENEL DEĞERLENDIRME}

Bankacılık sektörü ekonominin gelişmesi açısından en önemli etkenlerden biridir. Güçlü ve sağlıklı bankacılık sistemi, sürdürülebilir ekonomik büyüme için ön koşul olarak kabul edilmektedir. Rekabetin yoğun bir şekilde yaşandığı finans sektörü koşulları, bankaların kaynaklarını en etkin şekilde kullanmaya zorlamaktadır. Bu durum ise banka yöneticilerinin, kendi bankalarının etkinliklerini rakip bankalar ile karşılaştırma ihtiyacını ortaya çıkarmıştır.

Katılım bankalarının ekonomiye birçok katkısı vardır. Özellikle atıl fonların ekonomiye kazandırılması ve ekonomik büyümeye katkı sağlaması, yabancı kaynak transferi, vergi gelirleri açısından katılım bankaları son derece önemlidir. Güçlü ve sağlıklı bankacılık sistemi ve sürdürülebilir ekonomik büyüme için katılım bankalarının ekonomiye kazandırıması ve teşviklerin artırılması gerekmektedir.

Bu çalışmanın amacı 2012-2014 yıllarını arasında Türk Bankacılık Sektöründe faaliyette bulunan katılım bankaların finansal performansları Gri îlişkisel Analiz (GiA) yöntemi kullanılarak karşılaştırımıştır. Araştırmanın bir diğer amacı ise katılım bankasının 
performansını belirleyen finansal oranların sayısını azaltmak ve bu sayede hangi finansal oranın performans ölçümünde daha önemli olduğunu tespit etmektir. GíA yöntemi sonucunda finansal performans bakımından ilk sırada "Albaraka Türk" son sırada ise "Bank Asya" yer almıştır. Araştırma sonucunda elde edilen bir diğer bulgu ise "Varlık Karlıı̆̆ı" yüksek olan bir bankanın finansal performansının da yüksek olabileceği sonucuna ulaşılmıştır.

GiA yöntemini uygulayarak firma performansını ölçen çalışmalar incelendiğinde Chang (2006), Yuan (2007), Uçkun ve Girginer (2011), Doğan (2013) aynı yönde; buna karşın Ho ve Wu (2006), Peker ve Baki (2011) ile zıt yönde sonuçlar tespit edilmiştir.

GiA bankaların finansal performansını ölçmek ve yatırımcıların daha objektif ve daha doğru amaçlar belirlemesini sağlamak için önemli bir yöntemdir. Bu çalışmada 2012-2014 yıllarının verilerinden yararlanılması ve 10 finansal oranın kullanılması araştırmanın kısıtlarıdır. Gelecek çalışmalarda çok kriterli karar verme modellerinden AHS, TOPSIS, AAS ve ELECTRE gibi yöntemler bankalara uygulanarak bu araştırmanın sonuçları ile karşılaştırılabilir.

\section{KAYNAKÇA}

Baykara, H. V. (2012), "Katılım Bankalarında Etkinlik Ve Verimlilik Analizi”, Yayınlanmamış Yüksek Lisans Tezi, Gaziosmanpaşa Üniversitesi, Sosyal Bilimler Enstitüsü, Tokat.

Budak, H. (2011), "Veri Zarflama Analizi ve Türk Bankacılık Sektöründe Uygulaması”, Fen Bilimleri Dergisi, 23(3), 95-110.

Çetin, A. C. ve Bıtırak i. A. (2010), “Banka Karlılık Performansının Analitik Hiyerarşi Süreci İle Değerlendirilmesi: Ticari Bankalar İle Katılım Bankalarinda Bir Uygulam”, Alanya İşletme Fakültesi Dergisi 2/2, 75-92.

Chang, C. P. (2006), "Managing Business Attributes and Performance for Commercial Banks, The Journal of American Academy of Business, vol. 9 (1), pp. 104-109.

Doğan, M. (2013). Measuring Bank Performance with Gray Relational Analysis: The Case of Turkey. Ege Academic Review, 13(2),215-225.

Ece, N. (2011), “Dünya'da Ve Türk Bankacılık Sektöründe İslam Bankalarının Gelişimi”, -Akademik Bakış Dergisi, Uluslararası Hakemli Sosyal Bilimler E-Dergisi, Sayı: 25.

Ecer, F. ve Dündar, S. (2012) “Gri İlişkisel Analiz Yaklaşımıyla Türkiye'deki Özel Sermayeli Mevduat Bankalarının Performanslarının Ölçümü” 13.Uluslararası Ekonometri Yöneylem Araştırması ve Istatistik Sempozyumu, 24-26 Mayıs, Gazimağusa, K.K.T.C.

Elitaş, C., Eleren A., Yıldız, F. ve Doğan, M. (2012) “Gri İlişkisel Analiz ile Sigorta Şirketlerinin Performanslarının Belirlenmesi" 16. Finans Sempozyumu, 10-13 Ekim, Erzurum.

Ertuğrul, İrfan ve Karakaşoğlu Nilsen (2011), "Banka Şube Performanslarının Vıkor Yöntemi İle Değerlendirilmesi”, Endüstri Mühendisliği Dergisi, YA/EM 2008 Özel Sayısı Cilt: 20 Sayı: 1 Sayfa: 19-28.

Feng, C-M. ve Wang R-T. (2000), "Performance evaluation for airlines including the consideration of financial ratios", Journal of Air Transport Management, vol. 6, pp. 133-142.

Girginer N. ve Uçkun N. (2012) "The Financial Performance of the Commercial Banks In Crisis Period: Evidence From Turkey As an Emerging Market” European Journal of Business and Management, 4(19):19-36.

Ho, C-T. \& Wu Y-S. (2006) "Benchmarking performance indicators for banks", Benchmarking: An International Journal, Vol. 13 Iss: 1/2, pp.147 - 159. 
Hsu, C.-LÇ \& Wen, Y.-H. (2000), "Application of grey theory and multiobjective programming towards airline network design", European Journal of Operational Research, vol. 127(1), pp. 44-68.

Lee P.T.-W., Lin C.-W., Shin S.-H., (2012), "A comparative study on financial positions of shipping companies in Taiwan and Korea using Entropy and grey relation analysis, expert systems with applications", 39, 5649-5657.

Lin, C.-T. ve Hsu P-F. (2002) "Forecast of non-alcoholic beverage sales in Taiwan using the Grey theory", Asia Pacific Journal of Marketing and Logistics, vol. 14 Iss: 4, pp. 3-12.

Parlakkaya, R. C.. ve Suna A. (2011), "Finansal rasyoların katııım bankaları ve geleneksel bankalar arasında bir tasnif aracı olarak kullanımı: Türkiye örneği”, Ege Akademik Bakış, 2011,11(3):397-405.

Peker i. ve Baki B. (2011), "Gri ilişkisel analiz yöntemiyle Türk sigortacllık sektöründe performans ölçümü", Uluslararası iktisadi ve İdari İncelemeler Dergisi, vol. 4 (7), pp. 1-17.

Taşkın, F. D. (2011), “Türkiye'de Ticari Bankaların Performansını Etkileyen Faktörler”, Ege Akademik Bakış, Cilt: 11 - Sayı: 2 • Nisan 2011 ss. $289-298$.

Uçkun, N. ve Girgin N. (2011), “Türkiye'deki Kamu Ve Özel Bankaların Performanslarının Gri ilişki Analizi ile İncelenmesi", Akdeniz i.i. B.F. Dergisi (21) , 46-66.

Üstünışık, Naime Zerrin (2007), "Türkiye'deki iller Ve Bölgeler Bazında Sosyo Ekonomik Gelişmişlik Sıralaması Araştırması: Gri Illişkisel Analiz Yöntemi Ve Uygulaması", Yayınlanmamış Yüksek Lisans Tezi”, Gazi Üniversitesi Fen Bilimleri Enstitüsü.

Yayar, R. ve Baykara, H. V. (2012), "TOPSIS Yöntemi İle Katılım Bankalarının Etkinliği ve Verimliliği Üzerine Bir Uygulama". Business and Economics Research Journal, 3(4): 21-42. 